\title{
Dampak Model Pembelajaran BBL-Mind Map terhadap Kemampuan Berpikir Kritis Siswa dengan Kemampuan Awal Berbeda
}

\author{
Jumrotul Laili Mukaromah ${ }^{1}$, Suhadi Ibnu ${ }^{1}$, Subandi ${ }^{1}$ \\ ${ }^{1}$ Pendidikan Kimia-Universitas Negeri Malang
}

\section{INFO ARTIKEL}

\section{Riwayat Artikel:}

Diterima: 12-12-2019

Disetujui: $15-05-2020$

\section{Kata kunci:}

mind map;

critical thinking skills;

initial ability;

thermochemistry;

mind map;

kemampuan berpikir kritis;

kemampuan awal;

termokimia

\author{
Alamat Korespondensi: \\ Jumrotul Laili Mukaromah \\ Pendidikan Kimia \\ Universitas Negeri Malang \\ Jalan Semarang 5 Malang \\ E-mail: lailisay@gmail.com
}

\section{ABSTRAK}

\begin{abstract}
The purpose of study is know critical thinking skills of students who were taught using Brain Based Learning plus mind map in thermochemistry. The students consisted of two samples were different prior knowledge. The research design was a posttest-only design. The population for this study was all students of eleventh grade public high school 1 Wonoayu Sidoarjo, while the sample was taken from the population using cluster random, results of hypothesis test using two ways ANOVA showed that Brain Based Learning plus mind map and prior knowledge had effects to critical thinking skills. There was no interaction between learning model with prior knowledge to critical thinking skills thermochemistry.
\end{abstract}

\begin{abstract}
Abstrak: Penelitian ini bertujuan mengetahui berpikir kritis siswa berdasarkan kemampuan awal berbeda yang dibelajarkan dengan $B B L$ berbantuan mind map pada materi termokimia. Rancangan penelitian yang digunakan adalah rancangan eksperimen semu posttest-only design. Populasi berasal dari seluruh siswa kelas XI SMAN 1 Wonoayu Sidoarjo. Sampelnya diperoleh secara acak. Uji hipotesis dengan ANOVA dua jalur memperlihatkan jika model pembelajaran BBL-mind map dengan kemampuan awal berpengaruh pada kemampuan berpikir kritis. Tidak adanya dampak interaksi antara model pembelajaran dengan kemampuan awal terhadap kemampuan berpikir kritis siswa pada materi termokimia.
\end{abstract}

Kimia merupakan mata pelajaran terkait dengan sifat, struktur, hukum, prinsip, dan teori terhadap perubahan zat yang terjadi (Effendy, 2016). Berdasarkan berbagai penelitian yang antara lain dilakukan Hartiningsih (2018) di SMAN 1 Papar bahwa metode yang digunakan masih berupa ceramah, guru cenderung berpedoman pada buku teks saja, dan siswa masih belum dilibatkan secara penuh dalam pembelajaran. Siswa merasa pembelajaran kurang menarik sehingga siswa malas untuk berpikir atau mengoptimalkan penggunaan otaknya untuk memecahkan masalah. Berdasarkan observasi Hartiningsih (2018) di SMAN 1 Papar, metode pembelajaran yang digunakan masih metode ceramah, siswa masih belum dilibatkan secara aktif, kreativitas siswa dalam pembelajaran belum didukung sepenuhnya oleh guru, aktivitas dalam mengemukakan pendapat dan menjawab pertanyaan masih kurang, guru tidak memberikan umpan balik terhadap materi terkait, guru tidak mengecek pengetahuan yang telah dimiliki siswa terkait materi yang dibelajarkan, guru lebih cenderung berpedoman pada buku teks saja dan kurang inovatif, beberapa kegiatan dalam pembelajaran kimia dianggap tidak relevan terhadap kehidupan siswa, kurang memberi peluang untuk mengoptimalkan otak dalam memecahkan masalah sehingga siswa malas untuk berpikir (Raes \& Schellens, 2012).

Penggunaan otak akan maksimal jika siswa menggunakan otak kanan dan kiri secara seimbang dalam pembelajaran kimia, maka dapat menghindarkan siswa dari kebosanan. Kebosanan dalam kegiatan belajar membuat siswa jenuh sehingga membuat siswa kesulitan saat dibelajarkan materi kimia. Materi kimia yang masih dirasaa sulit oleh siswa adalah termokimia. Termokimia terdiri dari berbagai konsep, rumus, dan perhitungan matematika. Maka dari itu, diperlukan suatu pemahaman konsep dan matematis. Kesulitan yang dialami siswa pada termokimia disebabkan kurangnya penguasaan matematis siswa (Sokrat, Tamani, Moutaabbid, \& Radid, 2014). Selain itu, kesulitan siswa terjadai dikarenakan siswa masih belum mampu menghubungkan keterkaitan konsep dalam termokimia. Sesuai penelitian Andini (2018), siswa tidak dapat mengaitkan sub materi satu sama lain dengan benar. Berdasrkan penelitian (Riani, 2016) siswa kesulitan untuk membedakan antara suhu, kalor, juga entalpi; siswa sulit menentukan reaksi eksoterm endoterm Kesulitan siswa ini, mengakibatkan pemahaman siswa dan berpikir kritis siswa tentang termokimia masih rendah. Sesuai dengan pendapat Zaman, Choudhary, \& Qamar (2015) siswa yang memiliki pemahaman yang baik, menunjukkan siswa telah menggunakan kemampuan berpikir kritisnya dengan baik. 
Adanya berpikir kritis memiliki tujuan agar siswa lebih memahami materi pembelajaran dengan baik (Johnson, 2011). Maka perlu model bermakna dalam mengembangkan potensi otak untuk mengetahui kemampuan berpikir kritis, antara lain Brain Based Learning (BBL). Dibuktikan dengan beberapa penelitian, salah satunya adalah Duman (2010) dan (Noureen \& Awan, 2017) bahwa model $B B L$ dapat meningkatkan nilai akademik siswa.

Brain Based Learning (BBL) didasarkan pada penggunaan otak secara optimal, siswa akan memahami dan mengingat materi belajar dengan baik. Hal ini dikarenakan $B B L$ adalah pembelajaran berdasarkan penggunaan otak yang menekankan kegiatan belajar bermakna daripada menghafal (Akyurek \& Afacan, 2013). Menurut Jensen (2008), tahapan BBL terdiri dari tujuh tahapan. Setiap tahapan tersebut dapat mengembangkan pemahaman siswa menjadi lebih baik sehingga kemampuan berpikir kritis juga semakin membaik. Penggunaan $B B L$ akan optimal jika dibantu dengan mind map didukung oleh penelitian (Munfaridah, Yuliati, \& Diantoro, 2015) dan (Olaoluwa \& Ayantoye, 2016) bahwa BBL dengan mind map dapat meningkatkan pemahaman konsep siswa. Mind map digunakan untuk menunjukkan gambaran awal dalam memahami konsep yang akan diperoleh siswa, menggaitkan konsep satu sama lain dengan baik dan membuat pemahaman konsep siswa menjadi lebih baik (Lucy \& Rizky, 2012). Menurut Radix \& Abdool (2013), adanya mind map dapat mengaktifkan kemampuan awal siswa. Hal ini dikarenakan mind map adalah kegiatan menghubungkan konsep satu sama lain. Mengaktifkan pengetahuan sebelumnya, dapat meningkatkan pemahaman siswa terhadap informasi baru yang diperoleh. Dengan adanya pembuatan mind map, siswa dapat memetakan pemikirannya untuk lebih mudah memahami konsep baru (Gurlitt \& Renkl, 2010).

Kemampuan awal merupakan pengetahuan siswa terhadap konsep-konsep sebelumnya yang masih ada keterkaitannya dengan materi. Kemampuan atau pengetahuan awal adalah hal yang harus siswa miliki sebelum memeperoleh materi baru. Tujuannya agar termokimia dapat dipahami siswa dengan lebih baik. Sesuai pendapat McBride, dkk., (2010), adanya kemampuan awal yang dikelompokkan oleh guru sebelum pembelajaran dimulai, membuat siswa menjadi lebih paham dan dapat mengaitkan antar konsep. Pemahaman yang baik akan mengembangkan kemampuan berpikir kritis. Jadi, kemampuan siswa dalam berpikir kritis dapat dipengaruhi oleh kemampuan awal. Maka dari itu, dilakukan penelitian yang bertujuan untuk mengetahui kemampuan berpikir kritis dengan memperhatikan kemampuan awal siswa melalui Brain Based Learning berbantuan mind map pada materi termokimia.

\section{METODE}

Penelitian ini menggunakan quasi-experimental posttest-only design yang dikemumakan oleh Creswell (2012) seperti pada tabel 1. Rancangan penelitian ini digunakan untuk mengetahui pengaruh $B B L$ dengan atau tanpa mind map untuk berpikir kritis siswa pada materi termokimia dari kemampuan awal yang berbeda. Kemampuan awal dibagi dua, yaitu kemampuan awal tinggi dan rendah. Rancangan penelitian berdasarkan kemampuan awal menggunakan desain faktorial $2 \times 2$ yang ditunjukkan pada tabel 2.

Penelitian dilakukan sebanyak enam kali pertemuan, yaitu lima kali tatap muka dan satu hari untuk pelaksanaan ulangan harian termokimia. Pelaksanaan pembelajaran dilakukan 29 September-1 Oktober 2019. Penelitian dilakukan pada kegiatan pembelajaran dan pengambilan data nilai. Teknik untuk mengambil sampel adalah teknik cluster random sampling atau pemilihan sampel sebagai kelas eksperimen dan kontrol dilakukan dengan acak dari populasi semua siswa kelas XI SMAN 1 Wonoayu tahun ajaran 2019/2020,. Kelas eksperimen (N=36) adalah kelas XI MIPA 2 yang dibelajarkan dengan Brain Based Learning-mind map, untuk kelas kontrolnya $(\mathrm{N}=36)$ dari kelas XI MIPA 1 yang dibelajarkan dengan Brain Based Learning tanpa bantuan mind map.

Tabel 1. Rancangan Penelitian

\begin{tabular}{lcc}
\hline \multirow{2}{*}{ Model Pembelajaran } & \multirow{2}{*}{ Perlakuan } & \multicolumn{2}{c}{ Posttest $(\mathbf{O})$} \\
\cline { 2 - 3 } & $\mathrm{KBK}$ \\
\hline BBL menggunakan mind map & $\mathrm{X}$ & $\mathrm{KBK}_{1}$ \\
BBL tanpa mind map & - & $\mathrm{KBK}_{2}$ \\
\hline
\end{tabular}

Keterangan:

$\mathrm{O} \quad$ : posttest

$\mathrm{X} \quad$ : kelas eksperimen ( $B B L$ berbantuan mind map)

- $\quad$ : kelas kontrol yaitu kelas $B B L$

KBK : kemampuan berpikir kritis

Instrumen penelitian ini dikelompokkan menjadi dua, yaitu instrumen pembelajaran dan pengukuran (soal KBK). Pengujian instrumen menggunakan validasi isi dan validasi butir soal. Kemudian diukur validitas dan realibilitas dengan SPSS 22 for windows. 
Tabel 2. Rancangan Penelitian

\begin{tabular}{|c|c|c|}
\hline \multirow{2}{*}{ Kemampuan Awal } & \multicolumn{2}{|c|}{ Model Pembelajaran } \\
\hline & $\mathrm{BBL}+$ mind map & BBL \\
\hline Tinggi & $\mathrm{BBL}-$ mind map $-\mathrm{T}$ & BBL-T \\
\hline Rendah & $\mathrm{BBL}-$ mind map $-\mathrm{R}$ & BBL-R \\
\hline
\end{tabular}

\section{HASIL}

Hasil berupa observasi keterlaksanaan pembelajaran yang sesuai dengan RPP. Observasi pelaksanaan pembelajaran diamati oleh dua observer. Perolehan persentase rata-rata keterlaksanaan kedua kela dapat diketahui melalui gambar 2 . Kedua kelas sudah sama-sama terlaksana lebih dari 90\%. Oleh sebab itu, perbedaan yang diperoleh bukan disebabkan oleh keterlaksanaan pembelajaran yang berbeda.

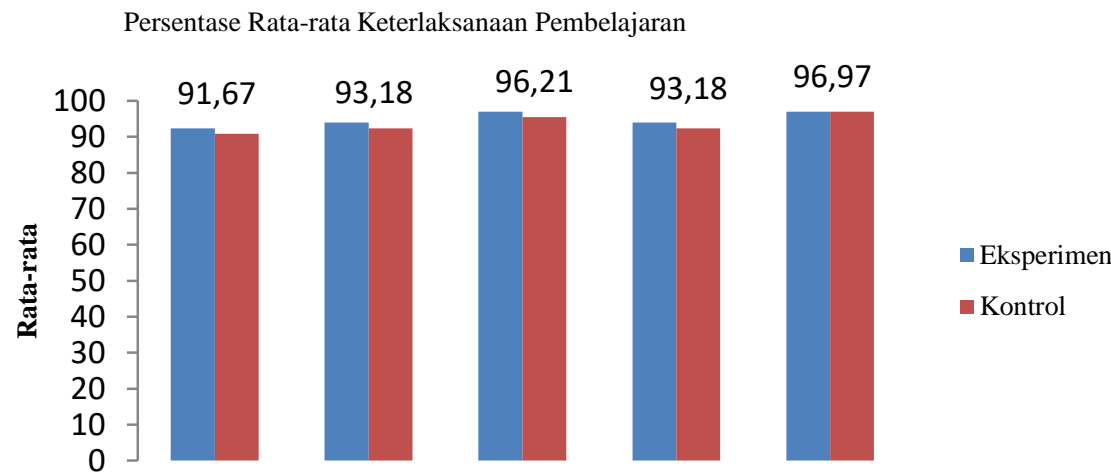

\section{Gambar 1. Persentase Rata-rata Keterlaksanaan Pembelajaran}

Kemampuan awal dikelompokkan menjadi kelompok awal tinggi dan kelompok awal rendah. Siswa yang memperoleh diatas skor nilai rata-rata ulangan harian materi stokiometri, ikatan kimia, dan hidrokarbon, akan dimasukkan ke dalam kelompok kemampuan awal tinggi. Sebaliknya, siswa yang mendapat dibawah skor nilai rata-rata kelas akan dimasukkan kedalam kelompok dengan kemampuan awal rendah. Nilai rata-rata kemampuan awal kelas dengan $B B L+m i n d$ map lebih tinggi di daripada kelas dengan $B B L$. Jumlah siswa dan profil nilai siswa di kedua kelas ditunjukkan pada tabel 3.

Tabel 3. Profil Kemampuan Awal Siswa

\begin{tabular}{|c|c|c|c|c|c|c|}
\hline Kelas & Rerata Nilai kelas X \& Hidrokarbon & $\begin{array}{c}\text { Nilai } \\
\text { Maksimal }\end{array}$ & $\begin{array}{c}\text { Nilai } \\
\text { Minimal }\end{array}$ & $\begin{array}{c}\text { Kelompok } \\
\text { Kemampuan Awal }\end{array}$ & $\begin{array}{c}\text { Jumlah } \\
\text { Siswa }\end{array}$ & $\begin{array}{r}\text { Total } \\
\text { Siswa }\end{array}$ \\
\hline \multirow{2}{*}{$\begin{array}{c}\text { Eksperimen }(B B L+ \\
\text { mind map })\end{array}$} & \multirow{2}{*}{73} & \multirow{2}{*}{100} & \multirow{2}{*}{36} & Tinggi & 20 & \multirow{2}{*}{36} \\
\hline & & & & Rendah & 16 & \\
\hline Kontrol $(B B L)$ & 71 & 98 & 38 & Tinggi & 18 & 36 \\
\hline
\end{tabular}

Melalui uji Kolomogrov Sminorv menunjukkan data terdistribusi normal atau probability signifikansinya $>0,05$, sesuai pada tabel 4. Uji Levene, menunjukkan bahwa kemampuan awal dengan $B B L+$ mind map dan $B B L$ saja memiliki varian homogen atau memiliki probability signifikansi $>0,05$, sesuai pada tabel 5 .

Tabel 4. Uji Normalitas untuk Kemampuan Awal

\begin{tabular}{lcccc}
\hline \multirow{2}{*}{ Kelas } & \multirow{2}{*}{ Mean } & \multicolumn{2}{c}{ Uji Kolmogorov-Sminorv } & \multirow{2}{*}{ Kesimpulan } \\
\cline { 3 - 4 } & & Std. Deviation & Sig & \\
\hline Eksperimen (BBL + mind map) & 73 & 13.959 & 0,069 & Normal \\
\hline Kontrol (BBL) & 71 & 14.371 & 0,090 & Normal \\
\hline
\end{tabular}

Tabel 5. Uji Homogenitas untuk Kemampuan Awal

\begin{tabular}{|c|c|c|c|}
\hline Kelas & Mean & Probability Signifikansi & Keterangan \\
\hline Eksperimen $(\mathrm{BBL}+$ mind map) & 73 & \multirow{2}{*}{0,646} & \multirow{2}{*}{ Homogen } \\
\hline Kontrol (BBL) & 71 & & \\
\hline
\end{tabular}


Tabel 6. Uji Kesamaan untuk Dua Rata-rata Kemampuan Awal Siswa

\begin{tabular}{lccc}
\hline \multicolumn{1}{c}{ Kelas } & Mean & Probability Signifikansi & Keterangan \\
\hline Eksperimen $(B B L+$ mind map) & 73 & 0,551 & Sama \\
\cline { 1 - 2 } Kontrol $(B B L)$ & 71 & & \\
\hline
\end{tabular}

Setelah mengetahui bahwa siswa memiliki kemampuan awal yang setara, peneliti memberikan tes kemampuan berpikir kritis termokimia di pertemuan terakhir sebanyak lima soal esai sesuai dengan indikator Ennis. Adapun perolehannya diketahui melalui tabel 7.

Tabel 7. Hasil untuk Kemampuan Berpikir Kritis

\begin{tabular}{lcccc}
\hline \multicolumn{1}{c}{ Kelas } & $\boldsymbol{N}$ & Mean & Nilai Maksimal & Nilai Minimal \\
\hline Eksperimen $(B B L+$ mind map $)$ & 36 & 80,97 & 100 & 60 \\
\hline Kontrol $(B B L)$ & 36 & 68,75 & 90 & 45 \\
\hline
\end{tabular}

Uji normalitas pada kelas $B B L+$ mind map dan $B B L$ saja untuk kemampuan berpikir kritis berdistribusi normal sesuai pada tabel 8, sedangkan pada tabel 9 menunjukkan pada kelas $B B L+$ mind map dan $B B L$ saja memiliki varian yang homogen.

Tabel 8. Uji Normalitas Berpikir Kritis

\begin{tabular}{lcccc}
\hline \multirow{2}{*}{ Kelas } & \multirow{2}{*}{ Mean } & \multicolumn{2}{c}{ Uji Kolmogorov-Sminorv } & \multirow{2}{*}{ Kesimpulan } \\
\cline { 3 - 4 } & & Std. Deviation & Sig & \\
\hline Eksperimen $(B B L+$ mind map $)$ & 80,97 & 12.061 & 0,098 & Normal \\
\hline Kontrol $(B B L)$ & 68,75 & 10.715 & 0,086 & Normal \\
\hline
\end{tabular}

Tabel 9. Uji Homogenitas Berpikir Kritis

\begin{tabular}{lccc}
\hline \multicolumn{1}{c}{ Kelas } & Mean & Probability Signifikansi & Keterangan \\
\hline Eksperimen $(B B L+$ mind map $)$ & 80,97 & 0,322 & Homogen \\
\hline Kontrol $(B B L)$ & 68,75 & & \\
\hline
\end{tabular}

Kemudian untuk kemampuan berpikir kritis siswa akan dikelompokkan dari kemampuan awalnya, yaitu tinggi dan rendah seperti pada pada tabel 10 .

Tabel 10. Kemampuan Berpikir Kritis Berdasarkan Kemampuan Awalnya

\begin{tabular}{cccccc}
\hline \multicolumn{1}{c}{ Kelas } & $\begin{array}{c}\text { Kelompok } \\
\text { Kemampuan Awal }\end{array}$ & $\boldsymbol{N}$ & Rerata & Nilai Maksimal & Nilai Minimal \\
\hline Eksperimen $(B B L$ & Tinggi & 20 & 84 & 100 & 65 \\
+ mind map) & Rendah & 16 & 77,19 & 95 & 60 \\
Kontrol $(B B L)$ & Tinggi & 18 & 80 & 100 & 60 \\
& Rendah & 18 & 65,28 & 80 & 45 \\
\hline
\end{tabular}

Siswa berkemampuan awal tinggi dan rendah di kelas $B B L+$ mind map, sama-sama memeperoleh nilai rerata lebih tinggi daripada kelas $B B L$ saja. Selanjutnya, uji hipotesis untuk ketiga variabel, yaitu $B B L$ sebagai model pembelajaran untuk kemampuan berpikir kritis siswa berdasarkan kemampuan awal berbeda menggunakan analisis ANOVA dua jalur sesuai tabel 11 .

Hasil uji hipotesis pertama menunjukkan bahwa probability signifikansi pada 'kelas' sebesar $0,003<0,050$. Maka kemampuan berpikir kritis yang dibelajarkan Brain Based Learning berbantuan mind map dan yang dibelajarkan dengan Brain Based Learning saja pada materi termokimia berbeda.Uji hipotesis kedua menunjukkan bahwa probability signifikansi pada 'kemampuan' sebesar 0,022 <0,050. Disimpulkan bahwa kemampuan berpikir kritis antara siswa berkemampuan awal tinggi dengan rendah pada materi termokimia berbeda. Uji hipotesis ketiga menunjukkan probability signifikansi pada 'kelas*kemampuan' sebesar 0,434 > 0,050. Disimpulkan bahwa dampak interaksi antara model pembelajaran yang diajarkan dengan kemampuan awal terhadap kemampuan berpikir kritis siswa untuk materi termokimia dinyatakan tidak ada. 
Tabel 11. Uji Hipotesis ANOVA Dua Jalur untuk BBL untuk Kemampuan Berpikir Kritis Berdasarkan

Kemampuan Awal Berbeda

\begin{tabular}{lrrrrr}
\hline \multicolumn{1}{c}{ Source } & Type III Sum of Squares & df & Mean Square & F & Sig. \\
\hline Kelas & 929,413 & 1 & 929,413 & 10,096 &, 003 \\
Kemampuan & 4472,049 & 23 & 194,437 & 2,112 &, 022 \\
Kelas * Kemampuan & 1152,791 & 12 & 96,066 & 1,044 &, 434 \\
\hline
\end{tabular}

\section{PEMBAHASAN}

Brain Based Learning dapat menaikkan motivasi belajar siswa atau siswa tidak ada keterpaksaan untuk belajar, sehingga hasil yang akan diperoleh siswa lebih baik (Akyurek \& Afacan, 2013). Setiap tahapan $B B L$ dapat mengaktifkan kemampuan berpikir kritis, karena melibatkan pemikiran dan otaknya melalui tahapan-tahapannya. Siswa diberikan soal-soal menantang, mendapatkan pengalaman belajarnya sendiri melalui praktikum, dan merasakan rileks saat pembelajaran. Adapun tiga dari tujuh tahapan $B B L$ yang memacu kemampuan berpikir kritis adalah elaborasi, inkubasi \& memasukkan memori, dan pengecekan keyakinan. Tahap elaborasi dan pengecekan keyakinan, siswa sama-sama diberikan soal-soal menantang, perbedaannya adalah siswa mencari kebenaran informasi sendiri pada tahap elaborasi. Pemberian soal-soal menantang dapat meningkatkan kemampuan berpikir siswa, yaitu berpikir kritis. Tahapan inkubasi dan memasukkan memori, siswa akan diperdengarkan musik dengan membaca kembali materi yang sudah didapatkan. Tujuan diperdengarkan musik agar siswa merasa lebih rileks, suasana menyenangkan, dan tidak tegang. Menurut (Kurniawati, Ghozali, \& Wartiningsih, 2014), pemutaran musik dapat meningkatkan konsentrasi dan menjadi lebih rileks. Pada tahap ini, siswa membaca ulang materi yang telah didapatkan.

Dalam memproses informasi, otak kanan dan kiri saling terhubung untuk menerima informasi tersebut melalui syarafsyarafnya. Dengan membaca ulang materi, siswa akan mengingat dan memahami kembali konsep yang telah diberikan, mengakibatkan syaraf-syaraf pada otak lebih banyak terhubung sehingga otak lebih mudah menyimpan informasi tersebut (Handayani \& Corebima, 2017). Adanya pengulangan membuat informasi yang diperoleh lebih mudah diingat siswa. Informasi yang diperoleh siswa akan mudah terlupakan begitu saja karena tersimpan di memori jangka pendek, agar informasi tersebut tidak mudah dilupakan maka perlu dilakukan pengulangan sehingga informasi akan tersimpan di memori jangka panjang (Schunk, 2012); (Kuswana, 2011); (Subanji, 2011). Salah satu informasi yang tersimpan dalam memori jangka pendek adalah hafalan tanpa pemahaman yang utuh (Thompson, 2011). Apabila informasi sudah tersimpan di long term memory, siswa akan mengingat lebih cepat saat informasi tersebut dibutuhkan. Sesuai dengan pemaparan sebelumnya bahwa $B B L$ dapat mengembangkan kemampuan berpikir kritis dibuktikan dengan perolehan probability signifikansi sebesar $0,003<0,05$. Penggunaan $B B L$ memberikan kesempatan siswa untuk mengoptimalkan fungsi otak sehingga kegiatan belajar lebih bermakna dan terjadi peningkatan dalam berpikir kritis. Berdasarkan skor nilai rata-rata berpikrir kritis menunjukkan jika kelas $B B L+$ mind map lebih tinggi dibandingkan kelas $B B L$. Hal ini dikarenakan adanya mind map yang digunakan dalam pembelajaran di kelas eksperimen.

$B B L$ berbantuan mind map dapat mengembangkan kemampuan berpikir kritis dalam bentuk individu juga kelompok. Secara individu, siswa diminta untuk mengungkapkan pengetahuannya di tahap pra-pemaparan dan persiapan melalui tanya jawab juga pembuatan mind map. Kemudian siswa melakukan praktikum percobaan dan presentasi secara berkelompok. Pada saat berkelompok, siswa diberikan pengalaman nyata (praktikum) dan menjawab tantangan soal, membuat kemampuan berpikir kritis siswa menjadi berkembang. Sesuai penelitian Handayani \& Corebima (2017), berkelompok adalah salah satu jenis hal yang dapat mengembangkan otak, siswa satu sama lain saling memberikan pendapat sesuai pemikirannya, sehingga dapat melatih berpikir kritis siswa. Kegiatan tersebut diharapkan siswa terbiasa untuk bekerja sama, saling bertukar pendapat, dan terlatihnya kemampuan berpikir kritis siswa. Sesuai penelitian Suprijono (2012), belajar dengan kelompok, siswa saling bertukar pikiran dan berkomunikasi dengan siswa lainnya. Belajar kelompok akan melatih siswa untuk saling mengomunikasikan dan bekerjasama dengan orang lain yang memiliki perbedaan karakter (Akbar, 2016). Selain itu, menurut (Soltani et al., 2017), berdiskusi bersama kelompok kecil dengan mengerjakan soal adalah dua hal dapat memberikan dampak yang baik untuk berpikir kritis.

Tahap persiapan di kelas eksperimen, siswa diminta untuk membuat mind map. Melalui mind map, siswa memperoleh gambaran awal untuk materi yang akan dipelajari. Siswa dapat menuangkan pemikirannya sesuai dengan kreativitasnya masingmasing, dapat berupa gambar dan juga tulisan warna-warni. Penggunaan gambar dan warna membuat informasi yang didapatkan siswa lebih mudah diingat, pembelajaran lebih menyenangkan, dan fungsi otak lebih optimal. Mencatat dan menghubungkan konsep menggunakan gambar dan warna dapat membuat pemahaman terhadap konsep lebih baik (Sumanik, 2018). Didukung pula oleh penelitian Buzan (2010) bahwa penggunaan warna akan lebih menarik, lebih hidup, memusatkan perhatian, meningkatkan fokus, lebih mudah diingat, dan menyenangkan. Pengoptimalan otak akan membantu siswa untuk menguasai konsep-konsep dengan lebih baik. Sesuai dengan pendapat (Lucy \& Rizky, 2012) dan (Santiago, 2011) menyatakan bahwa mind map sebagai alat yang efektif untuk menyeimbangkan dan menggunakan kedua otak secara optimal. Hal ini dikarenakan dalam pembuatan mind map, siswa tidak hanya menuliskan informasi atau pemikirannya saja, melainkan menghubungkan konsep satu dengan konsep lainnya sehingga kerja otak semakin optimal. Adanya mind map menunjukkan jika 
siswa lebih aktif mencari informasi yang berkaitan, menyusun konsep sendiri, dan menghubungkan konsep-konsep penting sehingga pembelajaran lebih bermakna karena informasi baru akan lebih mudah dipahami. (Yuniarti, Mulyani, \& Redjeki, 2014). Kemampuan individu dalam menghubungkan satu atau lebih informasi untuk memperoleh pengetahuan baru dalam memecahkan masalah disebut kemampuan berpikir kritis (Setyowati, 2011). Maka dari itu disimpulkan, kemampuan siswa dalam berpikir kritis lebih berkembang dengan adanya mind map. Sesuai hasil penelitian Safitri (2019), (Ristiasari, Priyono, \& Sukaesih, 2012), dan (Santiago, 2011) bahwa adanya mind map dapat membuat kemampuan berpikir kritis siswa lebih berkembang.

Kemampuan berpikir kritis siswa dengan kemampuan awal tinggi juga rendah pada kelas $B B L+$ mind map dengan kelas $B B L$ dapat dilihat melalui probability signifikansinya sebesar $0,022<0,05$. Menunjukkan kemampuan berpikir kritis siswa berkemampuan awal awal tinggi dan rendah dinyatakan berbeda. Kemampuan awal yang dimiliki siswa berhubungan terhadap kemampuan untuk menerima materi. Kimia memiliki materi yang saling terkait satu sama lain. Maka dari itu, siswa yang dapat memahami materi termokimia dengan baik disebabkan siswa telah memahami materi sebelumnya, seperti materi stokiometri dan hidrokarbon dengan baik. Faktor penentu untuk membelajarkan materi baru dalam pembelajaran adalah mengidentifikasi kemampuan awal. Siswa berkemampuan awal tinggi diasumsikan telah memiliki pemahaman lebih tinggi pada materi yang telah dan akan dipelajari. Sesuai dengan penelitian Eidswick (2010) menyebutkan bahwa pemahaman konsep yang tinggi dipengaruhi oleh pengetahuan awal yang tinggi dan pemahaman konsep yang rendah dipengaruhi oleh pengetahuan awal yang rendah. Pemahaman lebih tinggi yang dimiliki siswa menunjukkan bahwa siswa lebih mudah mengolah informasi dan menganalisis untuk memecahkan masalah dan menentukan solusi atas permasalahan yang telah diberikan. Kemampuan berpikir kritis adalah kemampuan yang dibutuhkan dalam mengolah informasi untuk menentukan solusi atas suatu permasalahan (Davies, 2011). Dengan demikian, kemampuan awal tinggi menunjukkan tingginya berpikir kritis pada siswa. Didukung pula Sardiman dalam (Danial, Gani, \& Husnaeni, 2017) berpendapat bahwa siswa kemampuan awal tinggi memiliki rasa ingin tahu dan keinginan belajar lebih tinggi sehingga berpotensi kemampuan berpikir kritisnya lebih tinggi.

Interaksi antara $B B L$ dibantu atau tanpa mind map dengan kemampuan awal berbeda terhadap kemampuan berpikir kritis siswa dinyatakan tidak ada. Diperoleh nilai probability signifikansinya sebesar 0,434>0,05. Dijelaskan oleh penelitian Safitri (2019) bahwa ketiga variabel pada materi laju reaksi tidak terjadi interaksi. Menurut Felder dan Brent (Puspaningrum, 2017) bahwa tidak adanya interaksi terhadap ketiga variabel tersebut karena adanya faktor lain yang memengaruhinya, yaitu gaya dan orientasi belajar. Selain itu, dikarenakan variabel bebas dan moderator sama-sama memberikan pengaruh kuat terhadap variabel terikat untuk semua kelompok sampel sehingga memungkinkan untuk tidak terjadi dampak interaksi. Sesuai dengan pendapat (Howell, 2011) menyatakan jika adanya variabel terikat dipengaruhi oleh dua variabel bebas sehingga interaksi antar variabel tidak akan terjadi. Dapat disimpulkan bahwa kemampuan awal dan model pembelajaran sebagai variabel bebas, sama-sama memberikan pengaruh kuat untuk kemampuan berpikir kritis sebagai variabel terikat.

\section{SIMPULAN}

Disimpulkan bahwa ada beda berpikir kritis pada siswa $B B L$ berbantuan mind map dengan $B B L$ saja dapat mengembangkan berpikir kritis. Ada beda berpikir kritis siswa berkemampuan awal tinggi lebih tinggi dan rendah. Model pembelajaran dengan kemampuan awal terhadap kemampuan berpikir kritis siswa pada materi termokimia tidak terlihat.

$B B L$ dengan bantuan mind map dapat meningkatkan kemampuan berpikir kritis siswa. Penelitian selanjutnya dapat menerapkan model pembelajaran serupa, yaitu $B B L$ dengan bantuan mind map terhadap variabel lain, seperti retensi belajar, motivasi belajar, HOTS, keterampilan proses sains, dan lain sebagainya. Penelitian selanjutnya dapat menerapkan $B B L$ dengan bantuan mind map terhadap materi kimia yang lain. Peneliti yang ingin melakukan praktikum untuk penelitian selanjutnya, disarankan untuk melakukan praktikum di lab untuk mengefektifkan waktu, menyadari pentingnya keselamatan di laboratorium, dan lebih menghayati secara mendalam terhadap apa yang dilakukan di laboratorium. Peneliti yang ingin menggunakan mind map untuk penelitian sebelumnya disarankan untuk memberikan penjelasan dan arahan pembuatan mind map sebelum pembelajaran berlangsung. Hal ini dinilai lebih efektif dan efisien.

\section{DAFTAR RUJUKAN}

Akbar, S. (2016). Best Practices Pendidikan Karakter. Best Practices Pendidikan Karakter. Malang: Universitas Negeri Malang. Akyurek, Erkan \& Afacan, O. (2013). Effects of Brain-Based Learning Approach on Students' Motivation and Attitudes Levels in Science Class. 3(1), 104-119.

Buzan, T. (2010). Buku Pintar Mind Map. Jakarta: Gramedia Pustaka Utama.

Creswell, J. W. (2012). Research Design Pendekatan Kualitatif, Kuantitatif, dan Mixed (Cetakan ke). Yogyakarta: Pustaka Pelajar.

Danial, M., Gani, T., \& Husnaeni, H. (2017). Pengaruh Model Pembelajaran dan Kemampuan Awal terhadap Kemampuan Berpikir Kritis dan Pemahaman Konsep Peserta Didik. Journal of Educational Science and Technology (EST), 3(1), 18.

Davies, M. (2011). Concept Mapping, Mind Mapping and Argument Mapping: What are the Differences and Do They Matter? Higher Education, 62(3), 279-301.

Duman, B. (2010). The Effects of Brain-Based Learning on The Academic Achievement of Students with Different Learning Styles. Educational Sciences: Theory \& Practice, 10(4), 2077-2103. 
Effendy. (2016). Ilmu Kimia untuk Siswa SMA dan MA Kelas X. Malang: Indonesian Academic Publishing.

Eidswick, J. (2010). Interest and Prior Knowledge in Second Language Reading Comprehension. JALT Journal, $32(2), 149-168$.

Gurlitt, Johannes \& Renkl, A. (2010). Prior Knowledge Activation : How Different Concept Processes, Learning Outcomes, and Perceived Self-Efficacy. Springer, 38, 417-433.

Handayani, B. S., \& Corebima, A. D. (2017). Model Brain Based Learning (BBL) and Whole Brain Teaching (WBT) in Learning. International Journal of Science and Applied Science: Conference Series, 1(2), 153-161.

Hartiningsih, T. (2018). Perbedaan Keterampilan Berpikir Kritis sebagai Dampak POGIL Berbantuan Advance Organizer dan POGIL Non Advance Organizer. 3(9)(2015), 1200-1203.

Howell, D. C. (2011). Fundamental Statistics for Behavioral Sciences (7 Edition). Wadsworth Publishing.

Jensen, E. P. (2008). Brain Based Learning (Cetakan ke; N. Yusron, Ed.). Yogyakarta: Pustaka Pelajar.

Kurniawati, L. D., Ghozali, I., \& Wartiningsih, A. (2014). Pengaruh Musik Klasik Karya W.A. Mozart terhadap Kecerdasan Emosional Kelas 5 SDN 06 Pontianak. Jurnal Pendidikan dan Pembelajaran, 3(8), 1-9.

Kuswana, W. S. (2011). Taksonomi Berpikir. Bandung: Remaja Rosdakarya.

Lucy, Bunda \& Rizky, A. J. (2012). Dahsyatnya Brain Smart Teaching (Cetakan 1). Jakarta: Penebar Plus.

Munfaridah, Nuril, Yuliati, Lia, \& Diantoro, M. (2015). Peran Mind Map dalam Model Brain Based Learning Berkaitan dengan Penguasaan Konsep Fisika. Seminar NasionaL Fisika dan Pembelajarannya, 116-122.

Noureen, G., \& Awan, R. (2017). Effect of Brain-based Learning on Academic Achievement of VII Graders in Mathematics. Journal of Elementary Education, 27(July 2018), 85-97.

Olaoluwa, S. A., \& Ayantoye, C. A. (2016). Impact of Brain-Based Instructional Strategy on Academic Performance of Deaf Students in Mathematics in Oyo School of Handicapped, Nigeria. World Journal of Educational Research, 3(2), $447-459$.

Puspaningrum, Y. (2017). Pengaruh Model Pembelajaran Learning Cycle 5E Berbantuan E-Scaffolding terhadap Hasil Belajar Kognitif dan Keterampilan Berpikir Kritis Mahasiswa pada Materi Unsur Golongan 11 dan 12 (Universitas Negeri Malang).

Radix, C., \& Abdool, A. (2013). Using Mind Maps for the Measurement and Improvement of Learning Quality. Caribbean Teaching Scholar, 3(1), 3-21.

Raes, A., \& Schellens, T. (2012). The Impact of Web-based Inquiry in Secondary Science Education on Students' Motivation for Science Learning. Procedia - Social and Behavioral Sciences, 69, 1332-1339.

Riani, B. (2016). Instrumen Pembelajaran Siswa SMK pada Materi Termokimia menggunakan Model Pembelajaran Search, Solve, Create, and Share (SSCS) Berbantuan Kartu Masalah. Proseding Semnas Pend. IPA Pascsarjana UM, 1.

Ristiasari, T., Priyono, B., \& Sukaesih, S. (2012). Model Pembelajaran Problem Solving dengan Mind Mapping terhadap Kemampuan Berpikir Kritis Siswa. Journal of Biology Education, 1(3), 34-41.

Safitri, M. A. D. (2019). Pengaruh Mind Mapping dalam Model Pembelajaran Argument Driven Inquiry (ADI) terhadap Hasil Belajar Kognitif dan Kemampuan Berpikir Kritis Siswa Kelas XI SMA dengan Kemampuan Awal Berbeda pada Materi Laju Reaksi. Tesis tidak diterbitkan. Universitas Negeri Malang, Malang.

Santiago, H. C. (2011). Visual Mapping to Enhance Learning and Critical Thinking Skills. Optometric Education, 36(3). Schunk, D. H. (2012). Learning Theories an Educational Perspective.

Setyowati, I. (2011). Pengaruh Variasi Media pada Cooperative Learning Cycle (CLC) 5E dan Kemampuan Awal terhadap Motivasi dan Hasil Belajar Siswa dalam Materi Laju Reaksi (Universitas Negeri Malang).

Sokrat, H., Tamani, S., Moutaabbid, M., \& Radid, M. (2014). Difficulties of Students from the Faculty of Science with Regard to Understanding the Concepts of Chemical Thermodynamics. Procedia - Social and Behavioral Sciences, 116, 368-372.

Soltani, A., Monajemi, A., Moosapour, H., Shahrtash, F., Tajik, M., Mirzazadeh, A., \& Mafinejad, M. K. (2017). Teaching Critical Thinking Across the Curriculum : A Main Competency for Medical Students at Tehran University of Medical Sciences. Medical Research Archives, 5(8).

Subanji. (2011). Teori Berpikir Pseudo Penalaran Kovariasional. Malang: Universitas Negeri Malang Press.

Sumanik, N. B. (2018). Pengaruh Penugasan Peta Pikiran dan Rangkuman pada Pembelajaran Model POGIL terhadap Literasi Sains dan Hasil Belajar Siswa pada Materi Hidrolisis Garam. Universitas Negeri Malang.

Suprijono, A. (2012). Cooperative Learning (Cetakan ke). Yogyakarta: Pustaka Pelajar.

Thompson, C. (2011). Critical Thinking Across the Curriculum : Process Over Output. International Journal of Humanities and Social Science, 1(9), 1-7.

Yuniarti, Mulyani, B., \& Redjeki, T. (2014). Pengaruh Pembelajaran Kooperatif Team Assisted Individualization (TAI) Dilengkapi Media Lingkaran dan Buku Saku terhadap Prestasi Belajar Siswa Materi Struktur Atom dan Sistem Periodik Kelas Xi Semester Ganjil Sma N 6 Surakarta. Jurnal Pendidikan Kimia, 3(1), 104-110.

Zaman, T. U., Choudhary, F. R., \& Qamar, A. M. (2015). Advance Organizers Help to Enhance Learning and Retention. International Journal of Humanities Social Sciences and Education, 2(3), 45-53. 